\title{
Um Encontro com a Didática: para uma Didática que Redimensione o Profissional Professor
}

\section{Resumo}

Na perspectiva de escrever sobre a Didática de forma a redimensionar o papel do profissional professor, este texto estará pondo em discussão três aspectos: (a) o trabalho do professor com o conhecimento, (b) a escola enquanto contexto de ação docente e (c) a formação e o desenvolvimento profissional do professor. A proposta básica é de se compreender a Didática como reflexão sistemática dos problemas da realidade educacional, para fundamentar a tese de que só se aprende a ser professor, quando se compreende a educação como projeto político cultural. Vale salientar que se trata de um estudo qualitativo, privilegiando uma abordagem interpretativa no tratamento dos dados coletados através de um estudo de caso e de histórias de vida de egressos da Didática, que atuavam como professores da rede pública de ensino nos anos de 1996 a 1998.

\section{Abstract}

This paper intends to put in discussion three aspects concerning the teacher 'role as a professional (a) the teacher's work with the knowledge, (b) the school as a environment for teaching action (c) the teacher's formation and professional development. The basic proposal is understanding the Didactics as a systematic reflection about educational reality problems so to base the thesis that someone only can be a teacher when the education is understood as a cultural political project. It's worthwhile to say that is a qualitative study with a interpretative approach of the collected data, through case studies and life stories of Didactics courses outgoing who were working as teachers in public schools on 1996 to 1998.

O fato de me perceber no mundo, com o mundo e com os outros me põe numa posição em face do mundo que não é de quem nada tem a ver com ele. Afinal, minha presença no mundo não é a de quem a ele se adapta, mas a de quem nele se insere. É posição de quem luta para não ser apenas objeto, mas sujeito também da História (Freire, 1997: 60).

Como a Didática pode redimensionar o profissional professor, para que ele se sinta sujeito da História e pense na educação como uma forma de intervenção no mundo?

Em vista de percorrer um caminho que nos leve a refletir sobre a Didática como um conhecimento que permita reelaborar a experiência profissional do aluno/professor, para que possamos pensar sobre a sua ação pedagógica, de forma a reorientá-la, parece-nos necessário tomar a prática como práxis.

Mas, o que significa isso? Como construir um movimento que parta da prática e a ela se volte, fazendo com que o professor compreenda que o seu trabalho docente exige reflexão crítica sobre a mesma? No intuito de pensar sobre as questões acima e valorizar os processos de reflexão na ação e de reflexão sobre a reflexão na ação (Schön, 1987), pretendemos, neste texto, abordar três idéias como problematização da Didática: o trabalho do professor com o conhecimento, a esco-

\footnotetext{
* Doutora em Educação pela Faculdade de Educação da Universidade de São Paulo. Mestra em Educação FE/USP. Licenciada em Letras pela USP. Licenciada em Música pela Universidade Federal do Rio de Janeiro e Pedagogia. Foi professora de escolas públicas nos estados de São Paulo e Rio de Janeiro (1974-1996) Professora das Faculdades Integradas "Campos Salles".
} 
la enquanto contexto da ação docente, e a formação e o desenvolvimento profissional do professor

Justificamos este caminho, porque, ao compreender a Didática como teoria e prática do ensino e da aprendizagem (conforme Pimenta, 1997,1998; Libâneo, 1992, 1998, entre outros), e problematizá-la, refletindo sobre as temáticas acima, buscamos assumir a posição de sujeito histórico e dar sentido e direção à história que fazemos.

\section{O trabalho do professor com o conhecimento}

Há que partir da ignorância, seguir um longo e difícil caminho, antes de chegar ao conhecimento. $O$ que é verdadeiro para o indivíduo é igualmente verdadeiro para a humanidade inteira: o imenso labor do pensamento humano consiste num esforço secular para passar da ignorância ao conhecimento (Lefebure, 1995: 50).

Do encontro do professor com o conhecimento é que se traduz o trabalho docente. $\mathrm{O}$ que consideramos conhecimento? Ato ou efeito de conhecer. Dar significado ao mundo. Lefevbre (1995: 49) diria que conhecer é um fato, porque ajo sobre as coisas, exploro-as, experimento-as; elas resistem ou cedem à minha ação, revelam-se; eu as conheço e aprendo a conhecê-las. O fato do conhecimento que tomo por ponto de partida para a reflexão teórica é o meu existir como ser histórico e como ser social, o "estar no mundo" como ser professor.

O trabalho do professor é este conhecer permanente, da exploração, da experimentação, das trocas de experiência, do esforço para passar da ignorância ao conhecimento. É o conhecer da aprendizagem de conhecer mais e melhor. É o conhecer do aprender a ensinar e do aprender a ser professor de determinados saberes e saber-fazeres. Saberes que partem, segundo Pimenta (1997, 1998a), das experiências de professor e/ou de aluno, dos saberes científicos e dos saberes pedagógicos. Saberes que se traduzem pela compreensão que fazemos da prática docente, de nosso trabalho de professores. Trabalho de aprender e apreender o significado da situação didática, o espaço das relações pedagógicas e a refletir junto sobre as formas desse conhecimento, revitalizando os processos humanos em fluxo. Compreender ("prender-com"), assim, a história humana em sua intersubjetividade, respeitando a subjetividade do outro e o compromisso pessoal com o aprender e o aprender a aprender, pois fora da intersubjetividade haverá apenas transmissão ou troca de informações. E o conhecimento é mais do que isso, é um processo que, para ser autêntico, precisa mover-se no sentido de conscientização ou transformação.

É evidente que o conhecimento sendo processo não ocorre em sua plenitude. E por isso, há que se pensar no conhecimento menos consciente, do senso comum, quando conhecemos o conhecimento existente, e na tomada de consciência, ou seja, na relação que estabelecemos entre a produção de conhecimento existente e a transformação de pequenos espaços/tempos de nossa realidade.

Conhecer é aprender. Aprender é a apropriação do existente, produzir o novo, ressignificar o mundo. Conhecer para o professor é, portanto, sentir e compreender a realidade - a escola e o espaço da sala de aula - para ser possível escolher conscientemente, tomar decisões, intervir, buscar constantemente o novo, problematizando o velho, fazer o régistro da história do grupo com o qual compartilhamos as múltiplas formas do conhecer.

E a Didática em relação ao trabalho do professor com o conhecimento? Como todo trabalho docente converge para assegurar a aprendizagem, a Didática, como teoria e prática do ensino, assim como disciplina, que estuda as tarefas de instrução e ensino, ajuda-nos a integrar os diversos campos do conhecimento humano para deles construir os saberes escolares que nos servirão para a finalidade de ensinar (Libâneo, 1992). 
Saberes que se desdobram em objetivos sociais e pedagógicos, nas especificidades de conteúdo e metodologia das matérias, em um saber controlar sistematicamente como os objetivos de aprendizagem se realizam durante o processo de ensino. Saberes que estruturam/organizam o trabalho docente, nos momentos de planejamento, execução e avaliação das atividades, buscando a transmissão/assimilação/produção (alguns diriam construção) consciente de conhecimentos, habilidades, hábitos e atitudes pelos alunos, assim como o desenvolvimento de suas capacidades cognoscitivas e sócio-emocionais.

A Didática ajuda-nos a refletir sobre a nossa prática de professor, o que é o mesmo que fazer pensar também sobre conhecimento e sobre o trabalho com o conhecimento. No caso: conhecimento sobre os professores e sobre o conhecimento dos professores. Isso significa que não basta trabalhar com o conhecimento, mas é fundamental saber como ele se relaciona (e tem se relacionado) com a prática docente, e como ele se constitui enquanto conhecimento profissional. Conhecimento este que afeta existencialmente o professor, em razão do trabalho que executa, do projeto político e cultural que leva em frente.

Alguns estudos têm apontado para a importância de conhecer a epistemologia do professor, buscando produzir conhecimento sobre os professores, centrando-se nos processos cognitivos do docente (Becker, 1993; Machado, 1995, entre outros). Para isso, procuram refletir sobre o que pensam os professores a respeito do conhecimento, quando ensinam conhecimento. Refletir sobre a relação que existe entre a concepção epistemológica do professor e sua prática pedagógica: o que pensam os professores enquanto planejam, executam e avaliam (e replanejam, e assim sucessivamente) as suas atividades pedagógicas. Tais pesquisas intencionam explicar a relação entre a reflexão e a ação. Relação esta que vai estruturando o pensamento do ser professor.

Outras análises pretendem enfocar mais as práticas pedagógicas e junto com os professores definir melhor o que seriam as teorias de ação - a epistemologia da prática (Schön, 1987; Marcelo García, 1992; Gómez, 1992; Zeichner, 1992; Pimenta, 1998b, entre outros). Vêem o conhecimento do professor, em relação à sua prática, como um caminho para superar a dicotomia entre o pensamento e a ação: o professor é o construtor de seu próprio conhecimento prático, profissional.

O que pretendemos, neste texto, é situarmos em relação à produção de conhecimento existente, para colocarmos o nosso ponto de vista a respeito. Apenas a vista de um ponto que nos inquieta e que traduzimos pelas indagações que se seguem: Mas, afinal, de que se trata este conhecimento prático e profissional? $\bigcirc$ que e como conhecem os professores? Quais as fontes deste conhecimento? Quais suas formas? Quais as categorias de conhecimento que poderiam ser problematizadas em um curso de Didática, para que o professor pudesse aprender a ser professor e ser sujeito também da História?

Como Lefebvre (1995: 49-50) nos ensina, em primeiro lugar, o conhecimento é prático, ele começa pela experiência e pela prática. Em segundo lugar, é nesta prática que o conhecimento se torna social, de relações cada vez mais ricas e complexas. E, finalmente, o conhecimento humano tem um caráter histórico.

Para enfrentar a realidade do trabalho docente, de forma crítica, levando em consideração os aspectos apontados por Lefebvre, de que o conhecimento é prático, social e histórico, importa refletir, brevemente, sobre o que entendemos por fontes, formas e categorias de conhecimento. Traçamos este caminho, porque ele nos mostra uma possibilidade (não a única) de buscar um certo conteúdo às formas que organizam a vida cotidiana de ser e estar professor, entre o vivido e o concebido (Lefebvre, 1991), a partir de nossas próprias experiências.

A primeira fonte do conhecimento refere-se à visão que o professor tem de sua prática como professor e como aluno. A segunda revela-se no conhecimento do professor sobre sua matéria de ensino: qual a natureza histórica, social e filosófi- 
ca do conhecimento com o qual escolheu trabalhar. E uma terceira fonte poderia se traduzir naquilo que o professor tende a conhecer, para que compreenda o processo de ensino e aprendizagem: conhecer o território do ensino, o espaço da relação pedagógica, a organização/estruturação do trabalho docente. Para Pimenta (1997, 1998a), estas fontes poderiam ser tratadas como saberes da docência, que seriam mobilizados pelos: saberes da experiência, saberes científicos e saberes pedagógicos.

Estas fontes ou saberes da docência, necessários para organizar o trabalho docente ou para ajudar a compreendê-lo melhor, tomam formas, quando o professor entra em contato com a prática da realidade da Escola (e da sala de aula): contexto especial de produção docente (Abdalla, 1999: 114).

Quais seriam, então, as formas do conhecimento que o professor privilegia em sua aula, na forma de organização do ensino (Libâneo, 1992: 177)? As formas com que o professor se aproveita das fontes do conhecimento, ao qual teve oportunidade de compreender durante suas experiências de vida, e, especialmente, nos programas de formação inicial, poderão acentuar alguns direcionamentos de ação e reflexão no modo de organizar o seu ensino.

Em correspondência com os saberes da experiência, saberes científicos e pedagógicos, os conteúdos do conhecimento que o professor coloca em ação vão tomando formas que possibilitam o encontro entre os alunos e a matéria.

A primeira forma se configura pelas propostas de encaminhamento, pelas intenções, pelos objetivos que são explicitados pelo professor, para que os alunos possam trabalhar junto com ele na (re)construção de seus conhecimentos. Poderíamos denominar esta forma de conhecimento proposicional ou conhecimento de intenções. $\mathrm{Na}$ verdade, seria a carta de intenções do professor, o seu plano de curso. Conhecimento que pode ser tecido se o professor souber trabalhar com as necessidades e expectativas de seus alunos, ou seja, compartilhando proposições ou intenções, para serem apreciadas em perpétua interação (Lefebvre, 1995: 49).

Os saberes científicos são entrelaçados com os saberes da experiência que o professor tem em relação ao desenvolvimento de seu curso. Quanto mais experiência o professor tiver, mais fácil será entender suas próprias propostas e transpô-las para os alunos de uma forma mais coerente e com mais significado (enriquecendo os seus saberes pedagógicos). Trata-se de um conhecimento proposicional, porque o professor toma decisões, traça um caminho, toma posições, mas tenta composiçôes com seus alunos.

A segunda forma poderia se traduzir na maneira como o professor desenvolve os seus propósitos. $\mathrm{O}$ modo como o professor compreende criticamente as idéias postas em seu plano de curso e as transpõe para seus alunos, até que se tornem saberes adquiridos, fazendo parte da aprendizagem efetiva dos alunos (Perrenoud, 1993: 25). Poderíamos denominar esta forma de conhecimento estratégico. Estratégico, no sentido etimológico, porque "arte de explorar condições favoráveis com o fim de alcançar objetivos específicos" (Ferreira, s/d: 586). Estratégico, porque o professor constrói saberes no espírito do aluno (Perrenoud, 1993: 25), estabelecendo relações com seus projetos e/ou experiências de vida.

Uma terceira forma poderia se configurar com o conhecimento das trocas de experiência ou estudos de caso, quando as trocas entre os alunos ou entre os alunos e o professor forem mais detalhadas/fundamentadas. Nesse sentido, o professor estaria enfatizando o conhecimento do particular, mas sem deixar de estar atento ao contexto e às suas inter-relações como um todo orgânico, e à sua dinâmica como um processo, uma unidade em ação (André, 1995: 31). Poderíamos configurá-lo como conhecimento de casos, pois representaria uma aproximação com o conhecimento da prática, ou seja, um modo de fazer a releitura das experiências do cotidiano, via investigação da prática. Ou seja, as condições e os materiais de criação do professor e de seus alunos seriam privilegiados, dando, assim, menos importância aos 
conhecimentos teóricos e à aplicação das receitas e modelos didáticos. Certamente, haveria outras formas de se trabalhar com o conhecimento, o que dependeria do entendimento e da compreensão que o professor tivesse de sua realidade educacional, de seu modo de existir e de ver o mundo. Formas estas que poderiam, também, ser orientadas pelos dois métodos do conhecimento anunciados por Marx (1966: 16):

É mister, sem dúvida - diz ele - distinguir, formalmente, o método da exposição do método de pesquisa. A investigação tem de apoderar-se da matéria, em seus pormenores, de analisar suas diferentes formas de desenvolvimento, e de perquirir a conexão íntima que há entre elas. Só depois de concluido esse trabalho, é que se pode descrever, adequadamente, o movimento do real.

Tanto o método da investigação (que nos permite um conhecimento direto da realidade), quanto o da exposição (meio pelo qual podemos nos apropriar do conhecimento já existente ou que nos ajuda a formular nossas explicações sobre a realidade, na perspectiva de compreendêla), podem servir de ponto de apoio para uma invenção permanente assim como conservação contínua (Pinto, 1979:378) do trabalho docente com o conhecimento.

Entretanto, formando um processo contínuo, não dá para pensar nas fontes e nas formas do conhecimento, sem pensarmos nas categorias que assume. Esta disposição tem apenas caráter lógico, de quem expõe algo, pois no viver concreto os professores unificam estas dimensões: 1. das finalidades sociais e educativas (para quê conhecer/ensinar/aprender?); 2. do conhecimento do currículo e da matéria de ensino (o quê conhecer/ensinar/aprender?); 3. do conhecimento dos alunos (como trabalhar com as relações interpessoais - aspectos cognoscitivos e sócioemocionais?); 4. do conhecimento pedagógico/didático (teorias e práticas que possam auxi- liar o professor nas diferentes situações didáticas e a enfrentar as questões metodológicas do dia-adia de ser e estar na profissão professor); e 5. do conhecimento do contexto (onde? quando? em que espaço social desenvolvemos o ato educativo?).

As fontes, as formas e as categorias do conhecimento (seja qual nome for atribuído), articulam, em nosso entender, a unidade teoria e prática - movimento de ação, reflexão na e sobre a ação - que o professor desenvolve através de seu trabalho. Trabalho que só terá sentido/significado se o professor estiver conectado com a realidade escolar, pois é no contexto da Escola (e da sala de aula), que ele pode mobilizar experiências e se produzir como pessoa e como profissional da educação.

\section{A escola como contexto da produção docente}

Eis aí o limite do pensar didático: ele não é a ação educativa. Mas o refletir que terá significado para ação, se partir da prática e a tiver como sentido (Pimenta, 1997: 49).

$O$ professor pode aprender a ser professor na Escola? A Escola pode aprender com o professor? E a Didática o que tem para nos ensinar?

As perguntas acima nos inquietavam, especialmente, quando acompanhávamos um egresso da Didática (turma de 96, Curso de Licenciatura/FEUSP), pesquisa $^{8}$ sob a coordenação da profa. dra. Selma Garrido Pimenta. Se o professor se fazia professor por conta de seu trabalho com o conhecimento, a Escola também exercia uma força em sua tomada de decisões, quando estava, principalmente, em sala de aula. Então, era preciso desvendar, um pouco mais, esta organização chamada Escola. Conhecer a Escola para conhecer o profissional professor. Conhecer a Escola e o professor, para ampliar os

\footnotetext{
${ }^{8}$ Pesquisa que foi intitulada "a didática na licenciatura - um estudo dos efeitos e um programa de curso na atividade
} docente de alunos egressos da licenciatura”, FE-USP, 1997. 
conhecimentos da Didática, enquanto teoria e prática do ensino.

Dessa pesquisa e de algumas histórias de vida, que pudemos coletar junto a alunos egressos da Didática (turmas 96 a 97), sob a orientação da respectiva professora, foi possível, a partir da análise dos dados coletados, estabelecer, pelo menos, quatro indicadores de que a Escola é o contexto da produção docente: a gestão escolar; o projeto político-pedagógico; a organização e articulação do currículo e o compromisso da Escola com o desenvolvimento profissional do professor.

Por que considerar a gestão escolar como propiciadora da produção docente, influenciando maneiras de ser e estar na profissão? Qual o significado para o professor da gestão escolar? Se a gestão escolar existe para tornar vivo o projeto político-pedagógico pensado pela equipe da Escola, de forma a organizá-la e criar condições para sua transformação, o que inclui criar oportunidades para construção e reconstrução coletiva de saberes, podemos dizer que o professor, ao participar deste processo, reconhece-se como profissional e age como tal.

Quando a escola permite relações mais flexíveis e menos autoritárias, o professor aprende a explorar possibilidades, trocar experiências com seus pares, trabalhar com o coletivo. A escola torna-se ponto de encontro dos vários profissionais envolvidos na ação educativa, permitindo a participação, o debate de idéias, a tomada de decisões mais coerente e integrada. A gestão torna-se democrática, porque os professores tornam-se parceiros da Escola. A gestão democrática impulsiona o espaço das interações sociais, do enriquecimento possível dos alunos e de seus professores, da reconstrução contínua do projeto político-pedagógico da Escola, ressignificando a profissão professor.

E por que considerar o projeto políticopedagógico como uma das possibilidades de reconstruir-se profissionalmente? $\bigcirc$ projeto políticopedagógico é o que vai dar vida à gestão democrática, porque é ele que será o eixo condu- tor de todo o trabalho que se faz na escola. É nele que o professor investe seu lado profissional. E é através dele que os professores se organizam, estruturando e transformando a própria Escola.

A construção do projeto político-pedagógico é, segundo Veiga (1995: 22), a própria organização do trabalho pedagógico da escola. E, para participar dessa organização, é necessário desempenhar funções que busquem conhecer coletivamente e continuamente as necessidades e expectativas da escola; as dificuldades de aprendizagem dos alunos; os problemas de evasão e repetência; o rendimento escolar; problemas de (in)disciplina/violência; as questões administrativas e educacionais; o contexto geral da escola; o desenvolvimento profissional dos professores.

Entre os problemas relacionados com o envolvimento do professor com o projeto político da escola, as temáticas da organização e articulação do currículo e o desenvolvimento profissional do professor surgiram, nas falas dos professores, indicando a Escola enquanto contexto de produção docente. Senão vejamos.

A organização e articulação curricular é o espaço conceitual e de intervenção do professor. Espaço conceitual, porque é concebido como um campo de reflexão e de conhecimento. Espaço de desenvolvimento dos aspectos cognoscitivos que tornam o movimento do ato de ensinar no ato de aprender. Espaço de significação de ser e estar professor. Este pensar ficou, de alguma forma, registrado nas falas que se seguem:

Eu tenho que fazer isso com os alunos: os alunos não são coisas, não são objetos da minha auto-realização, da minha auto-afirmação como professor. Eles não são nada disso: são sujeitos desse processo de conhecimento. Aliás, eu acho que são dois sujeitos, ou melhor, um sujeito composto: aluno/professor. Então, e o objeto? O objeto é o conhecimento, não é? ... que serve para juntos - professor e alunos construirmos uma nova sociedade que, no caso, seria justa (prof. Juarez, Filosofia, egresso da Didática/ 1996).

Na sala de aula, você tem que acreditar que 
aquilo que você está falando é importante, e é por isso que o aluno tem que ouvir, e depois você tem que estar falando coisas seguras, coisas... prováveis, não é? Então, você quer convencer também. (...) com certeza você tem que falar no que é verdadeiro. $\mathrm{O}$ que eu vou falar para esta moçada? Eu vou falar de futebol? Não, vou falar de outra coisa. E eu sempre tive uma preocupação, assim, com a questão da muTher, a questão das minorias, e tudo mais... Sempre me interessaram. No CEFAM, elas (as mulheres) são maioria. Mas, na sociedade, elas são minoria, enquanto participação. Então, todos os meus cursos - Metodologia de História, História da Educação e outros - nos possibilitaram refletir sobre as questões: por que as mulheres na Antiguidade não aprendiam nada? Por que a Educação era para os homens? (...) E eu estava cumprindo o meu papel, era honesto em fazer isto. E o que era melhor: eu podia tocar na vida delas, na realidade delas, mas eu estava sendo honesto com o meu compromisso também com a Escola. (prof. Francisco, História, egresso da Didática/1997, in Abdalla, 1997).

Quando professores, como Juarez, Francisco, e tantos outros, organizam e articulam os conteúdos curriculares, estão desenvolvendo tarefas cognoscitivas que são compartilhadas com os alunos, tais como: os objetivos da aula, os conteúdos - problemas a serem resolvidos -, a metodologia de trabalho - atividades, exercícios, e o processo de avaliação - um vaivém entre o que o professor coloca e o conhecimento prévio dos alunos para resolverem as tarefas. E é, nessa disposição, que os professores se (re) constroem enquanto profissionais da educação, indicando que a Escola, enquanto contexto de ação reflexão - ação, é a base da formação e do desenvolvimento destes profissionais.

Se a Escola é, para o professor, a base de sua formação e desenvolvimento profissional, porque contexto de seu trabalho, de sua ação docente, $\mathrm{o}$ que significa para a Escola desenvolver profissionalmente seus professores?

Os depoimentos dos professores nos mostram o quanto a Escola está distante de saber o significado de formar e desenvolver profissionalmente o quadro de seu corpo docente, apesar das inovações, como: o projeto político-pedagógico, o horário de trabalho coletivo (HTPCs), a salaambiente, os ciclos, os Programas de Educação Continuada (PECs), entre outras.

O projeto pedagógico, para funcionar, tem que se mover em toda uma discussão, mas a praticidade disso, necessita, também, de uma participação da própria direção. (...) A mesma coisa com a salaambiente, ela não funciona se o professor continuar a dar sua aula tradicional, porque não adianta $o$ aluno mudar de uma sala para outra e chegar um pouco mais cansado ou mais agitado. É a única diferença se o professor não mudar a postura dele. Ele tem que começar a enxergar esta diferença, tem que começar a ver outros horizontes, tem que começar... (prof. Silas, Geografia, Didática/96).

Eu tive um problema muito sério no ano passado e retrasado com a escola em que eu dava aula, pública, que era justamente a incapacidade de estar trabalhando coletivamente com os outros professores, porque eu até levantei isso no curso de Didática, várias vezes, porque não era possível fazer um projeto sério, efetivamente, porque é aquele velho discurso, "tudo é uma droga" e o "Estado está sabotando", "o que eles querem é passar todo mundo" etc. Que existe até um fundo de verdade, mas se a gente ficar parado só nisso, não anda e não faz nada. A coisa está posta, a gente tem que dar um jeito de trabalhar com o que se tem. E, nessa semana que passou, já nesse novo colégio, eu senti uma abertura muito maior, e acho que vai ser muito produtivo, porque os professores mesmo já estavam se organizando na HTPC, para estar discutindo, estar trabalhando, trocando experiências, trazendo coisas novas, discutindo autores (prof. Jair, História, Didática/97) (Abdalla, 1997).

São raras as Escolas que prevêem um trabalho de formação contínua com seus professores, esquecendo-se que esta talvez fosse a chave para que a Escola pudesse contar com um corpo de professores permanente e compromissado com a 
qualidade do ensino que todos almejamos. Um programa de formação contínua e desenvolvimento profissional dos professores faz da Escola o contexto de ação do professor. Ação que delineia finalidades para o projeto da escola e permite acreditar que as mudanças são possíveis e necessárias.

\section{A formação e o desenvolvimento do professor}

Queremos remodelar a educação docente como projeto político, como uma política cultural que defina os professores em formação como intelectuais cuja vontade estabeleça espaços públicos nos quais os estudantes possam debater, apropriar-se e aprender o conhecimento e habilidades necessárias para atingir a liberdade individual e a justiça social (Giroux, 1997: 203-204).

É possível pensar que o professor aprende a ser professor? E no que a Didática poderá contribuir com a formação e desenvolvimento deste profissional, para que ele possa compreender a educação docente como projeto político e política cultural?

Cada vez mais os programas de formação de professores, tanto inicial quanto contínua, vêm observando que é preciso trabalhar com conhecimentos, habilidades, atitudes que permitam aos professores compreender as complexas situações didáticas que precisam enfrentar. Isso significa desenvolvê-los profissionalmente em uma atitude de reflexão crítica sobre a prática. Mas de que prática falamos? O que entendemos por formação e desenvolvimento profissional?

Para formar, no sentido de concretizar o desenvolvimento profissional do professor, como intelectual capaz de lutar por espaços necessários, pensamos que é fundamental compreender, em primeiro lugar, o nosso próprio processo de formação. Tomamos, então, emprestado a idéia de perspectiva retroativa de Nóvoa (1988: 107-130), de que a formação deve ser entendida como uma tomada de consciência reflexiva (presente) de toda uma trajetória de vida percorrida no passado, com a intenção de projetar-se para o futuro. É, nesta direção, que pretendemos definir alguns pressupostos, que poderão nortear a tese de que só se aprende a ser professor, quando se compreende a educação como projeto político e cultural:

1ำ Para pensar em uma educação como projeto político e cultural, é preciso questionarmos como as nossas experiências humanas foram sendo produzidas no interior das escolas por que passamos (até, e principalmente, como alunos). Reconhecer, como propõe Giroux (1997: 204), que as escolas são instituições históricas e culturais que sempre incorporam interesses ideológicos e politicos, parece-nos um bom início de conversa, para que possamos problematizar as diferentes formas de política cultural que existem na escola, e servem para organizar e legitimar maneiras de ser e de estar na profissão (Abdalla: 1999).

$2^{2}$ Tratar a educação docente como projeto político e cultural é compreender que a formação do professor (tanto inicial, quanto contínua) se faz na ação, na produção (ou construção) de conhecimentos, e não em seu consumo. Mas uma ação que possa articular o conhecimento como um modo filosófico de investigar a própria realidade, na produção de experiências vividas e vivificadas.

3ำ A inserção profissional do professor tem seu início na formação inicial. Espera-se que, neste período, seja dado valor à dimensão da prática de formação profissionalizante como núcleo de desenvolvimento pessoal do futuro professor (Alarcão, 1996: 47). Desenvolvimento pessoal, que se transfere para profissional, fazendo da formação, como nos revela Nóvoa (1988: 128), um processo de transformação individual, na tripla dimensão do saber (conhecimento), do saberfazer (capacidades) e do saber-ser (atitudes).

4으 A transferência do desenvolvimento pes- 
soal para o profissional se dá na medida em que se valoriza o exercício do trabalho como o pólo decisivo do processo de produção de profissionalidade (Canário, 1997: 1). Trata-se de situar as questões de formação no contexto da escola, uma vez que a escola é o contexto de ação do professor (Marcelo Garcia, 1994: 11-40; González González, 1992: 71-95).

5 - Uma das chaves do desenvolvimento profissional se encontra na ação de planejar, o que implica traçar metas, tendo em vista atingilas. Segundo Marcelo Garcia (1994: 24-25), isso significa que o professor tem que estar em um permanente compromisso de atualização pessoal e profissional. As possibilidades do professor viver em atualização constante passam por ressignificar a profissionalização docente. E, nesse sentido, as decisões políticas precisam investir mais na formação contínua de nossos professores. Formação que seja mais coletiva, tendo em vista a transformação dos espaços concretos da escola. Portanto, é na ação de planejar que são analisadas as necessidades do conjunto de professores (e seus alunos). Nesses momentos de troca de experiên- cias é que se produzem saberes e se negociam projetos que vão permitir delinear novos percursos, novos objetivos indutores de formação (Barbie e Lesne, in Rodrigues \& Esteves, 1993: 24) e de profissionalização.

E a Didática, como ela pode redimensionar e ressignificar a profissão professor?

Ao interligar a teoria e a prática, a Didática, enquanto reflexão sistemática dos problemas da realidade educacional, possibilita o exercício de uma experiência formativa, na medida em que o aluno (futuro professor) reconhece-se membro pertencente e participante de um produto político-cultural, que é oriundo dos esforços e tentativas materiais de toda uma coletividade. Experiência formativa, que permita promover discussões e reflexões, com o intuito de questionar as práticas educativas existentes, possibilitando o desenvolvimento de consciências críticas - de sujeitos que possam tomar a teoria e torná-la força prática e transformadora, na posição, como nos diz Freire, de quem luta para não ser apenas objeto, mas sujeito também da História.

\section{REFERÊNCIAS BIBLIOGRÁFICAS}

ABDALLA, Maria de Fátima B. Relatório de pesquisa: A didática na licenciatura -um estudo dos efeitos e um programa de curso na atividade docente de alunos egressos da licenciatura / coordenação Selma G. Pimenta. São Paulo: FE-USP, 1997. . O senso prático de ser e estar na profissão: das necessidades da prática. In: REUNIÃO

\section{ANUAL DA ASSOCIAÇÃO NACIONAL DE PÓS-GRADUAÇÃO E PESQUISA EM}

EDUCAÇÃO, 22, 1999, Caxambu, MG. Anais... . Caxambu/Minas Gerais: ANPEd, 1999. p. 114 (resumo).

ALARCẨO, Isabel. A Experiência Portuguesa. In: MENEZES, L.C. (org.). Professores: formação e profissão. Campinas:

Autores Associados; São Paulo : NUPES, 1996b, p.33-69.

ANDRÉ, Marli Elisa D.A. Etnografia da prática escolar. Campinas: Papirus, 1995.

BECKER, Fernando. A epistemologia do professor: o cotidiano da escola. 3. ed. Petrópolis : Vozes, 1993.

CANÁRIO, Rui. A escola: o lugar onde os professores aprendem. In: CONGRESSO NACIONAL DE SUPERVISÃO NA FORMAÇÃ̃ , 1, 18-20, Aveiro, 1997. Aveiro, Universidade de Aveiro, 1997. (mimeogr.).

FERREIRA, Aurélio Buarque de Holanda. Novo Dicionário da Língua Portuguesa. Rio de Janeiro: Nova Fronteira, [19--].

FREIRE, Paulo. Pedagogia da Autonomia: saberes necessários à prática educativa. 2.ed. São Paulo: Paz e Terra, 1997.

GIROUX, H. Os professores como intelectuais: rumo a uma pedagogia crítica da aprendizagem. Porto Alegre : Artes Médicas, 1997.

GÓMEZ, Angel Pérez. O pensamento prático do professor: a formação do professor como o profissional reflexivo. In: NÓVOA, A. Os professores e a sua formação. Lisboa: Publicações Dom Quixote, 1992. p.93-114.

GONZÁLEZ GONZÁLEZ, M.T. Centros escolares y cambio educativo. In: ESCUDERO, J.M. \& LÓPEZ, J (orgs.). Los desafios de las reformas escolares. Sevilla : Arquetipo, 1992. p.71-95.

LEFEBVRE, Henri. A vida cotidiana no mundo moderno. São Paulo: Ática, 1991. 
. Lógica formal/Lógica Dialética. 6.ed. Rio de Janeiro: Civilização Brasileira, 1995.

LIBÂNEO, José Carlos. Didática. São Paulo : Cortez, 1992.

. Pedagogia e Pedagogos, para quê? São Paulo: Cortez, 1998.

MACHADO, Nílson José. Epistemologia e Didática: as concepções de conhecimento e inteligência e a prática docente. São Paulo : Cortez, 1995.

MARCELO GARCÍA, Carlos. A formação de professores: novas perspectivas baseadas na investigação sobre o pensamento do professor. In NÓVOA, A. Os professores e a sua formação. Lisboa : Publicações Dom Quixote/Instituto de Inovação Educacional, 1992, p. 51-76.

. Formación del professorado para el cambio educativo. Barcelona : Promociones y Publicaciones Universitarias/PPU, 1994.

MARX, Karl. O Capital. Rio de Janeiro : Civilização Brasileira, 1996. Livro 1, v.1, 1.

NÓVOA, Antônio. A formação tem de passar por aqui : as histórias de vida no Projecto Prosalus. In: NÓVOA, A. \& FINGER, M. (coords). O método (auto) biográfico e a formação. Lisboa : Ministério da Saúde/Departamento de Recursos Humanos da Saúde/Centro de Formação e Aperfeiçoamento Profissional, 1988. p.107-130.

PERRENOUD, Philippe. Práticas Pedagógicas, Profissão Docente e Formação: perspectivas sociológicas. Lisboa : Publicações Dom Quixote, Instituto de Inovação Educacional, 1993.

PIMENTA, Selma Garrido. A Didática como mediação na construção da identidade do professor : uma experiência de ensino e pesquisa na Licenciatura. In: ANDRÉ, M. E. D.A. \& OLIVEIRA, M.R.N.S. Alternativas do Ensino de Didática. Campinas: Papirus, 1997. p. 37-69.

. Formação de Professores: saberes da docência e identidade do professor. In: FAZENDA, I.

(org.). Didática e Interdisciplinaridade. Campinas: Papirus, 1998a. p.161-178.

. A Prática (e a teoria) docente ressignificando a Didática. In: OLIVEIRA, M. R.N.S. (org.).

Confluências e Divergências entre Didática e Currículo. Campinas : Papirus, 1998b. p. 153-176.

PINTO, Álvaro Vieira. Ciência e existência. Problemas filosóficos da pesquisa científica. 2.ed. Rio de Janeiro : Paz e Terra, 1979.

RODRIGUES, Ângela \& ESTEVES, Manuela. A análise de necessidades na formação de professores. Porto: Porto Editora, 1993.

SCHÖN, Donald. Educating the Reflective Practitioner. Toward a New Desing for Teaching and Learning in the Professions. San Francisco : Jossey Bass, 1987.

VEIGA, Ilma Passos A. (coord.). Projeto político-pedagógico da escola: uma construção possível. Campinas: Papirus, 1995.

ZEICHNER, Kenneth. Novos caminhos para o practicum: uma perspectiva para os anos 90 .

In: NÖVOA, A. Os professores e a sua formação. Lisboa: Publicações Dom Quixote / Instituto de Inovação Educacional, 1992. p. 115-138. 